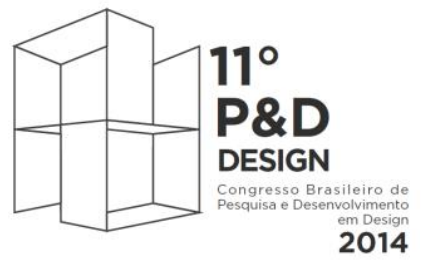

\author{
Gramado - RS
}

De 29 de setembro a 2 de outubro de 2014

\title{
DESIGN DA INFORMAÇÃO: Desenvolvimento e Seleção de Personagens para Material Informativo, Aplicado à Educação em Saúde Pediátrica
}

\author{
Dra. Eleida Pereira de Camargo \\ Universidade de São Paulo; Universidade São Judas Tadeu e Faculdades Oswaldo \\ Cruz/FAITER \\ eleidapc@gmail.com \\ Dr. Gilmar Fernandes do Prado \\ Universidade Federal de São Paulo \\ gilmarunifesp@yahoo.com.br
}

\section{RESUMO}

O ronco, a apneia obstrutiva do sono (SAOS) e a síndrome das pernas inquietas (SPI) são distúrbios do sono prevalentes e ainda pouco reconhecidos principalmente pela população infantil, importante multiplicador da informação, fundamental para prevenção de doenças e suas consequências. Este estudo tem por finalidade desenvolver e selecionar personagens para série de histórias em quadrinhos (HQ) sobre Distúrbios de Sono, futuramente utilizadas em ações de educação em saúde. Dois desenhistas foram instruídos a criar personagens que representassem quatro condições do sono: normal, ronco, SAOS e SPI. Os nomes e características das personagens basearam-se em dados técnicos, culturais e étnicos da população. Foram desenvolvidas duas versões de desenhos: (V1) que apresentava estilo "manga" e (V2) que representava a neotenia. Para a seleção de uma destas versões, ambas foram submetidas à votação por 124 escolares (6 a 10 anos) e 26 adultos, especialistas em educação e/ou comunicação. Comparamos os IC $95 \%$ para os pares de cada grupo. Consideramos significante $p<0.05$. Os nomes e personagens elaborados foram Soninha para sono normal, Ronco para o roncador, Baba para a SAOS e Formiga para o portador de SPI. Foram selecionados Soninha e Formiga V1 (70.7\%; 76\%); Ronco e Baba V2 (65.3\%; 51.3\%). Não houve diferença significante entre escola de procedência, mas sim entre a seleção das faixas etárias, acentuadamente para a personagem Soninha, preferida na versão V2 pelos adultos e V1 pelas crianças $(\Delta 43.6 \%$ Soninha; 49.2\% Ronco e 26.8\% Formiga, $p<0,05$; IC 95\%). Criamos e selecionamos 4 personagens para representar o sono normal e 3 prevalentes distúrbios do sono: Soninha (normal), Ronco (roncador), Baba (SAOS) e Formiga (SPI), que protagonizarão futura série de histórias em quadrinho sobre Distúrbios de Sono.

Palavras-chave: design gráfico, design da informação, educação em saúde 


\section{ABSTRACT}

Snoring, obstructive sleep apnea (OSA), and restless legs syndrome (RLS) are prevalent sleep disorders that are poorly recognised mostly by child population, and are an important source of information for preventing disease and its consequences. This study aims to develop and select characters for a comic book series (CB) about sleep disorders to be used in health education.

Two designers were asked to create characters that represent four sleep conditions: normal, snoring, OSA, and RLS. We developed two versions of the drawings: (V1) "manga" style and (V2) neoteny style. 124 students (ages 6 to 10 years) and 26 adult education and/or communication specialists were asked to select the version they preferred $(\mathrm{Cl} 95 \%$; $P<0.05)$. The characters were as follows: Soninha for a normal sleep, Ronco for the snorer, Baba for OSA, and Formiga for the patient with RLS. V1 versions of Soninha and Formiga were selected (70.7\%, 76\%); V2 versions of Ronco and Baba were selected (65.3\%, 51.3\%). There was no significant difference in choices associated with the students' school of origin, but there was a significant difference between the age ranges. The V2 version of Soninha was preferred by the adults, and the V1 version was preferred by children ( $\Delta$ 43.6\% Soninha, 49.2\% Ronco, and 26.8\% Formiga). We created and selected four characters to represent normal sleep and three disordered sleep conditions: Soninha (normal sleep), Ronco (snoring), Baba (OSA), and Formiga (RLS), who will be protagonists in a comic book series about sleep disorders.

Keywords: graphic design, information design, health education

\section{INTRODUÇÃO}

A alta prevalência dos distúrbios de sono e suas múltiplas comorbidades os tornam um tema relevante para a saúde coletiva, tanto adulta quanto pediátrica (PARTINEN, HUBLIN, 2000; SANTOS-SILVA et al., 2009; MACHADO et al., 2006). Quando estes distúrbios se manifestam em uma idade precoce, trazem consequências para toda a família pois crianças acometidas solicitam sistematicamente a intervenção de um adulto, principalmente durante o sono. Algumas das implicações de ordem cognitiva, comportamental e física, decorrentes destas doenças são: déficit de crescimento, dificuldades de aprendizagem, distúrbios comportamentais e hipodesenvolvimento craniofacial (JULIANO et al., 2009; BALBINI et al., 2005). O diagnóstico precoce amplia as possibilidades de tratamentos menos intrusivos e mais eficazes (CARVALHO et al., 2005; GOZAL, O’BRIEN , ROW, 2004).

Inúmeros materiais impressos são desenvolvidos com o objetivo de promover a saúde coletiva, mas recorrentemente são concebidos sem que haja uma interação entre os envolvidos: profissionais de saúde, designers e pacientes (ROZEMBERG, SILVA, VASCONCELOS-SILVA, 2002). Na ação de promoção e comunicação em saúde há o predomínio da visão do especialista em detrimento das expectativas do público ao qual esta ação se destina e são escassas as informações sobre o processo de desenvolvimento e formulação destes materiais (WERNER, BOWER, 1982; Ottawa Charter for Health Promotion, 1986; CAMARGO et al., 2011). Para que a intervenção seja eficiente é fundamental que seja considerado o perfil de seu público-alvo (FAWDRY, 1994; TEIXEIRA, CYRINO, 2003). 
Diante destas constatações, buscamos desenvolver uma ação de conscientização direcionada à população infantil por meio de recursos didáticos que privilegiam a comunicação visual em detrimento da alfabética. Esta estratégia comunicacional considera também que parte da população adulta atendida nos serviços de saúde pública do país, tem baixa escolaridade ou não é alfabetizada. (CAMARGO et al., 2011)

"Uma imagem fala mais do que 1000 palavras" Esta máxima da comunicação visual tem ainda maior poder argumentativo se aplicada ao paciente pediátrico. As razões podem estar relacionadas ao fato de que, diferentemente do que ocorre com a escrita, a imagem apresenta uma compreensão imediata, pois não pressupõe o domínio de um código específico como o alfabético. A manifestação gráfica é uma forma de expressão humana que antecede o registro da linguagem oral. Os desenhos rupestres datam de 30.000 anos antes de cristo e constituem os alicerces de toda a comunicação escrita da humanidade, seja ela alfabética, ideográfica ou simbólica (COX, 1992; DONDIS, 1973; RAMA et al., 2004; MARNY, 1968; FRUTIGER, 1999). Talvez esta seja uma das razões pelas quais os quadrinhos sejam o gênero de leitura preferido entre crianças e jovens 5 a 16 anos (RAMA et al., 2004; SCHALL et al., 1986). A História em Quadrinhos (HQ) reune harmonicamente a linguagem escrita e o desenho e é reconhecida como importante meio de comunicação de massa.

Este estudo tem por objetivo desenvolver e identificar a melhor concepção visual para os personagens de uma série de histórias em quadrinhos sobre distúrbios de sono, a ser elaborada futuramente. A série abordará o ronco, a higiene do sono, a síndrome da apneia obstrutiva do sono (SAOS) e a síndrome das pernas inquietas (SPI), e será dirigida a crianças de 6 a 10 anos de idade, inicialmente atendidas no serviço de saúde pública.

\section{DESENVOLVIMENTO}

A concepção das personagens levou em conta o perfil sócio demográfico da população do ambulatório Neuro-sono, um serviço do sistema público de saúde; o nível de conhecimento desta população sobre os principais distúrbios de sono; as características clínicas associadas às doenças selecionadas; a diversidade étnica da população brasileira; os gêneros; as faixas etárias; a popularidade do mangá e da neotenia nos desenhos de cartoon. Os aspectos técnico-científicos foram obtidos por meio de contato com os profissionais de saúde envolvidos neste serviço, e também da participação dos desenhistas junto às atividades do corpo clínico do ambulatório.

Este processo de concepção das personagens foi precedido de 2 etapas: 1) caracterização do público-alvo 2)seleção do conteúdo informativo. A caracterização do público-alvo consistiu-se no levantamento das doenças prevalentes e do perfil sóciodemográfico da população ambulatorial do departamento de Neuro-Sono da Universidade Federal de São Paulo (UNIFESP). A seleção do conteúdo informativo baseou-se no conhecimento prévio destes pacientes em relação as suas possíveis doenças mensurando grau de concordância entre queixa referida pelo paciente na anamnese e posterior hipótese diagnóstica realizada pelo profissional de saúde (CAMARGO, et al., 2013; CAMARGO et al., 2011).

A partir destes levantamentos, optamos por inserir no material instrucional 6 temas principais: sono normal, síndrome do ronco, higiene do sono, síndrome da apneia 
obstrutiva do sono (SAOS), síndrome das pernas inquietas (SPI) e o exame de polissonografia, que revelaram-se prevalentes e/ou pouco conhecidos da população atendida neste serviço especializado.

As evidencias clínicas associadas ao ronco, SAOS, SPI, nortearam a concepção de 4 personagens principais a serem desenvolvidas para futura série de histórias em quadrinhos: 1)narrador sem manifestação de doença, 2)um apneico, 3)roncador e 4)portador da síndrome das pernas inquietas. Sob a revisão técnica de um neurologista, uma pediatra e uma psicóloga, a elaboração das personagens contemplou características físicas e comportamentais dos pacientes portadores dos distúrbios apresentados, como: irritabilidade, alteração craniofacial e diminuição da curva pondero-estrutural em apneicos; obesidade nos roncadores e agitação e desconforto nos membros inferiores, relacionados a SPI.

Estas manifestações clínicas influenciaram também diretamente a denominação das personagens: a que apresenta sono normal foi chamada de Soninha, diminutivo do nome Sonia, de origem russa que significa sábia, próxima da ciência. Além do aspecto etimológico, a sonoridade deste nome foi levada em conta, uma vez que se assemelha à palavra "sono" (do latim somnu), diretamente associada ao tema. A personagem apneica (Alessandra) foi apelidada de Baba e faz referência a uma característica de crianças portadoras de SAOS, que por apresentarem respiração oral frequentemente, tendem a babar durante o sono. O roncador foi apelidado de Ronco, referindo-se a manifestação clínica da doença e o portador de SPI foi apelidado de Formiga em decorrência da queixa recorrente destes pacientes, que descrevem a sensação de desconforto como um formigueiro nas pernas.

Além das diretrizes pertinentes ao estado de saúde das personagens este desenvolvimento levou em conta também critérios psicológicos e educacionais. Com o objetivo de despertar maior identificação e empatia, optamos por representar crianças na mesma faixa etária do público pretendido, de ambos os gêneros, desenvolvendo duas personagens femininas (Soninha e Baba) e duas masculinas (Ronco e Formiga). Ilustramos também a diversidade étnica presente na população brasileira (caucasianos, negros e orientais).

As mesmas orientações foram fornecidas a desenhistas distintos que desenvolveram duas diferentes concepções visuais para cada um dos protagonistas: Uma mais próxima ao estilo oriental Mangá (V1, Figura 1), hoje popularizada também entre os adolescentes e pré-adolescentes ocidentais, e outra conformação visual que se aproxima mais da representação da anatomia humana infantil (neotenia), com cabeça e olhos superdimensionados (V2, Figura 2). 

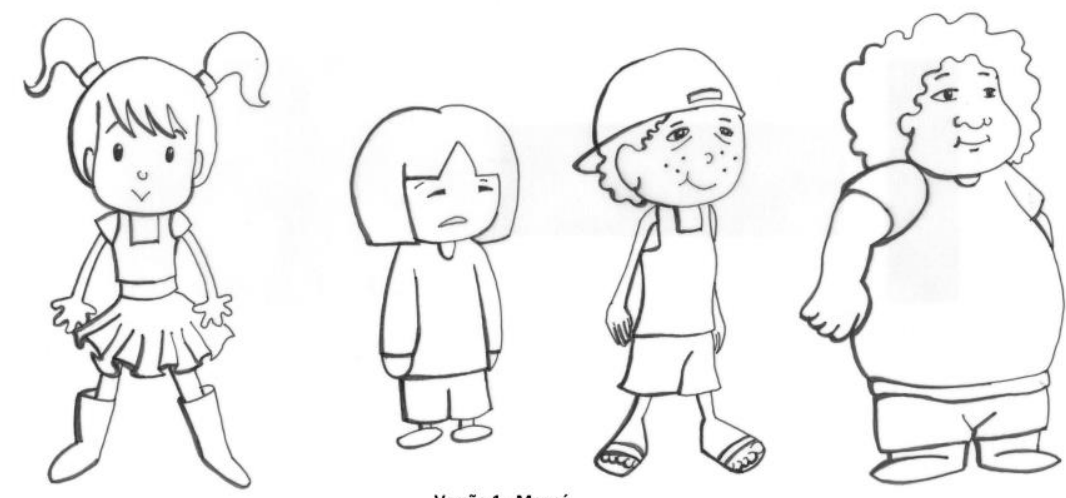

Figura 1. Personagens da série V1 (Mangá), onde são representados da esquerda para a direita: Soninha, Bába, Formiga e Ronco (imagens elaboradas pelo autor, com base na pesquisa realizada)
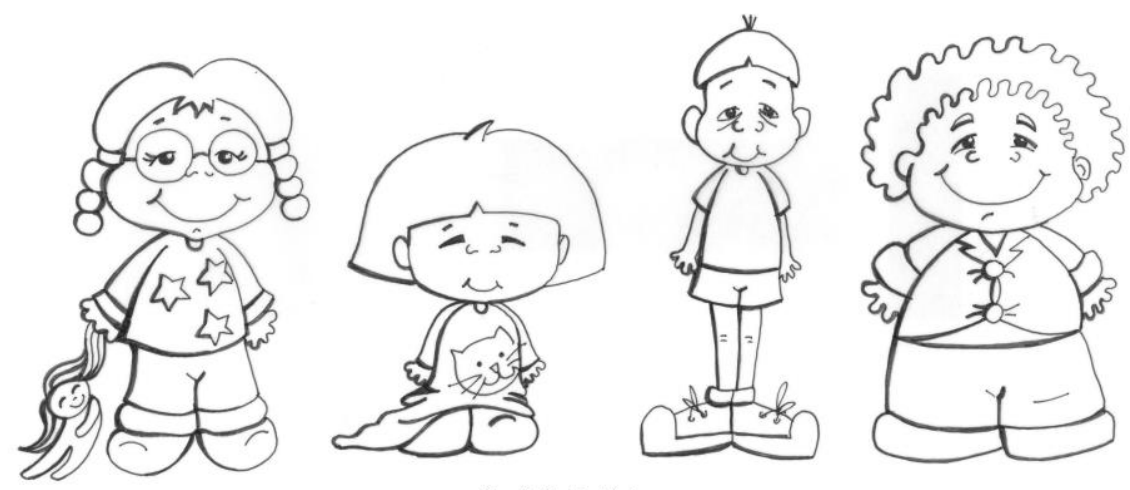

Versão 2 - Neotônica

Figura 2. Personagens da série V2 (Neotenia). Da esquerda para a direita: Soninha, Bába, Formiga e Ronco. (imagens elaboradas pelo autor, com base na pesquisa realizada)

Além das orientações baseadas nas manifestações clínicas, características físicas, comportamentais, psicológicas e étnicas, os desenhistas foram orientados a desenvolver desenhos á traço, sem preenchimentos, texturas ou tratamentos gráficos de complexidade pois a simplicidade do traço pode ajudar a criança a identificar a representação das personagens com seu próprio desenho e permite também, que ela venha a fazer suas próprias intervenções na imagem, colorindo-a ou hachuriando-a.

\section{Seleção das Personagens}

Com o objetivo de identificar qual as duas versões de desenhos desenvolvidas seria de maior interesse do nosso público submetemos os desenhos a uma votação.

Para calcularmos o tamanho da amostra, levamos em conta que a cidade de São Paulo apresenta cerca de 11 milhões de habitantes, dos quais 820.537 são crianças entre 6 e 10 anos de idade matriculadas no ensino fundamental nas redes pública e privada. A amostra calculada foi de 150 indivíduos (erro amostral de 7\% e IC=95\%) dos quais 26 eram adultos especialistas (educadores e/ou comunicadores) e 124 eram crianças, de 6 a 10 anos de idade, onde 86 cursavam a 1a série, 12 cursavam a 2aㅡ, 16 crianças pertenciam a 3ạ e 10 crianças à 4a série. As 2 escolas participantes e as salas de aula foram selecionados por sorteio. A amostragem levou em conta as 2 redes do sistema de ensino do país: 
pública ( $n=61$ ) e privada ( $n=63$ ), com o objetivo de verificar resultados em subgrupos socioeconomicamente distintos.

O estudo foi aprovado pelo Comitê de Ética em Pesquisa da Universidade Federal de São Paulo (UNIFESP) sob o protocolo de número 0850/05. Os responsáveis pelas instituições de ensino assinaram o termo de consentimento com a aprovação dos pais.

\section{Levantamento de dados}

Nas respectivas escolas, durante o horário regular de aulas, os alunos foram chamados um a um pelo pesquisador. A cada entrevistado foram apresentados os 4 personagens, em suas 2 versões visuais (V1 e V2). Em um cartão havia as imagens de Soninha 1 e Soninha 2; em um outro cartão foram representadas Bába 1 e Bába 2; em um terceiro cartão, estavam Ronco1 e Ronco 2 e no quarto cartão Formiga 1 e Formiga 2 (Figura 3). A medida que o pesquisador mostrava a cada criança um dos cartões, solicitava oralmente que escolhesse o "personagem de que mais gostava", entre as 2 versões, V1 ou V2.
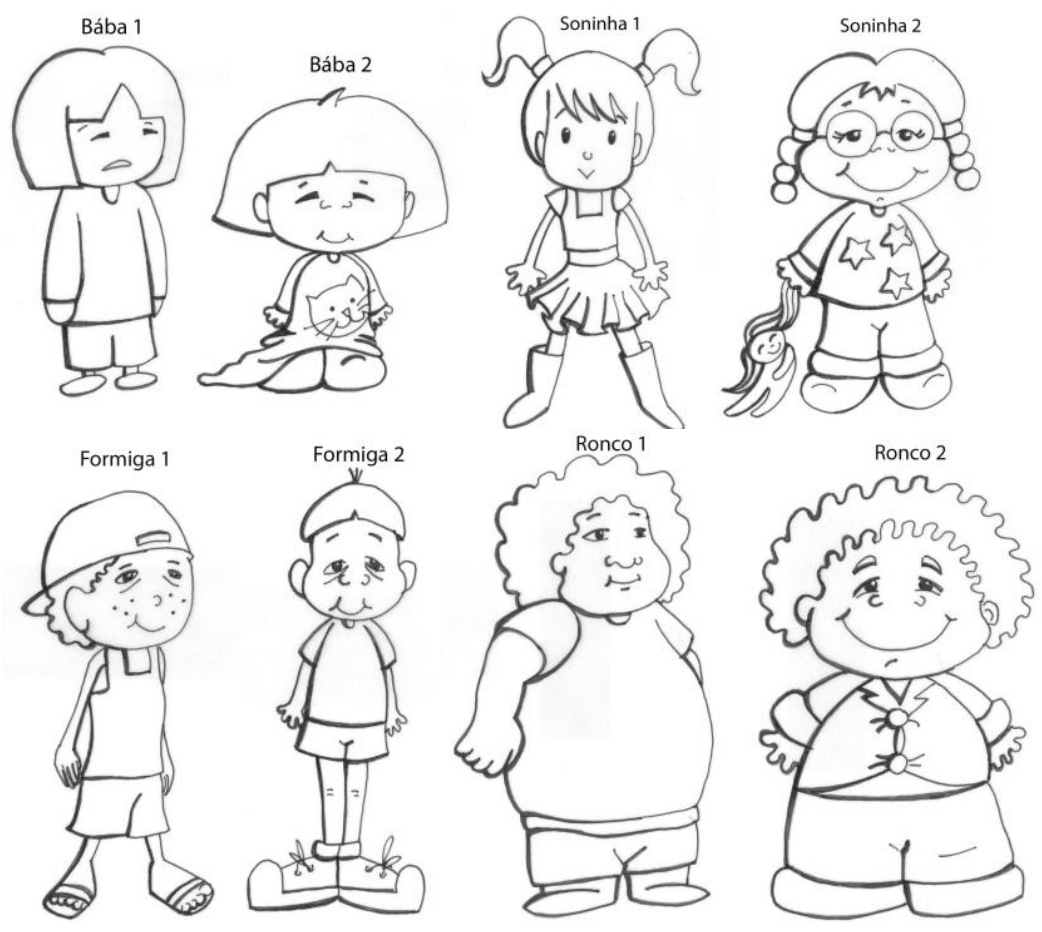

Figura 3. Quatro cartões utilizados para a votação das personagens desenvolvidas (imagens elaboradas pelo autor, com base na pesquisa realizada).

Os resultados eram marcados, em uma folha separada para que fosse mantido o sigilo do voto e a criança não tivesse acesso à opção dos colegas no transcorrer de seu processo individual de escolha. Com o objetivo de minimizar a influência exercida pelo grupo durante este procedimento, os alunos também foram impossibilitados de se comunicar até que toda a votação fosse concluída, evitando que, ao comunicarem-se imediatamente após sua escolha, os estudantes optassem pela personagem que havia sido votada pelo colega. 
Os 26 especialistas também foram consultados individualmente, utilizando-se o mesmo quadro de opções.

Após a solicitação de escolha de cada dupla de personagens, perguntamos aos participantes a razão da preferência assinalada. Interrompemos a inclusão de respostas quando se atingiu o critério de saturação dos dados (PARKER, 2004).

Os dados foram analisados por meio de estatística descritiva e foram comparados os intervalos de confiança, para cada uma das variáveis, com o propósito de se analisar as prevalências e significâncias entre os subgrupos da amostra (adultos, crianças, séries e escola de procedência). Foi considerado significante $p<0,05$.

\subsection{Resultados}

Os participantes que compuseram a amostra global $(n=150)$ selecionaram os seguintes personagens: Soninha 1 (70.7\%, n=106 p<0,05; IC95\%: 0.634-0.78 a 0.220-0.366) Bába 2 (65.3\%; $n=98$, IC 95\%; $p<0,05 ; 0.271-0.423)$; Ronco 2 (51.3\%; $n=77, p>0,05$; IC 95\%; 0.4070.567 ) e Formiga 1 (76\%; $n=114, p<0,05$; IC 95\%; 0.692-0.828 a 0.172-0.308) . Na amostra global foram selecionados personagens das duas versões desenvolvidas, sendo dois deles pertencentes a versão 1 (Soninha e Formiga); um da versão 2 (Baba) e outro que não apresentou diferença significante entre as duas versões (Ronco).(Gráfico 1).

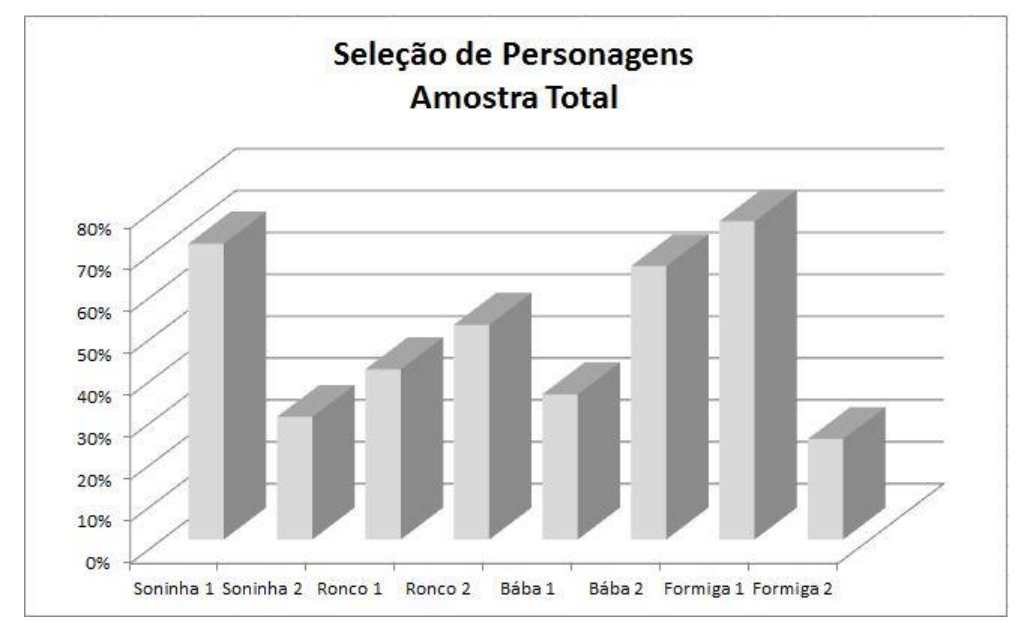

Gráfico 1. Seleção da amostra global ( $n=150$ ) (gráfico elaborado pelo autor, com base na pesquisa realizada)

Entre as crianças $(n=124)$ as personagens Soninha 1 (78.2\%), Bába $02(62.1 \%)$, Ronco 2 (50.8\%) e Formiga 1 (80.6\%) obtiveram o maior percentual de votos. Entre os 26 especialistas entrevistados os personagens selecionados foram: Soninha 2 (65.38\%); Bába 2 (80.77\%); Ronco 2 (100\%) e Formiga 1 (53.85\%).

As crianças preferiram a personagem Soninha $1(78,2 \%)$ e os adultos a personagem Soninha 2 (65,5\%). Para as demais personagens a seleção de crianças e adultos foi igual Baba 2, Ronco 2, Formiga 1. (Gráfico 2) 


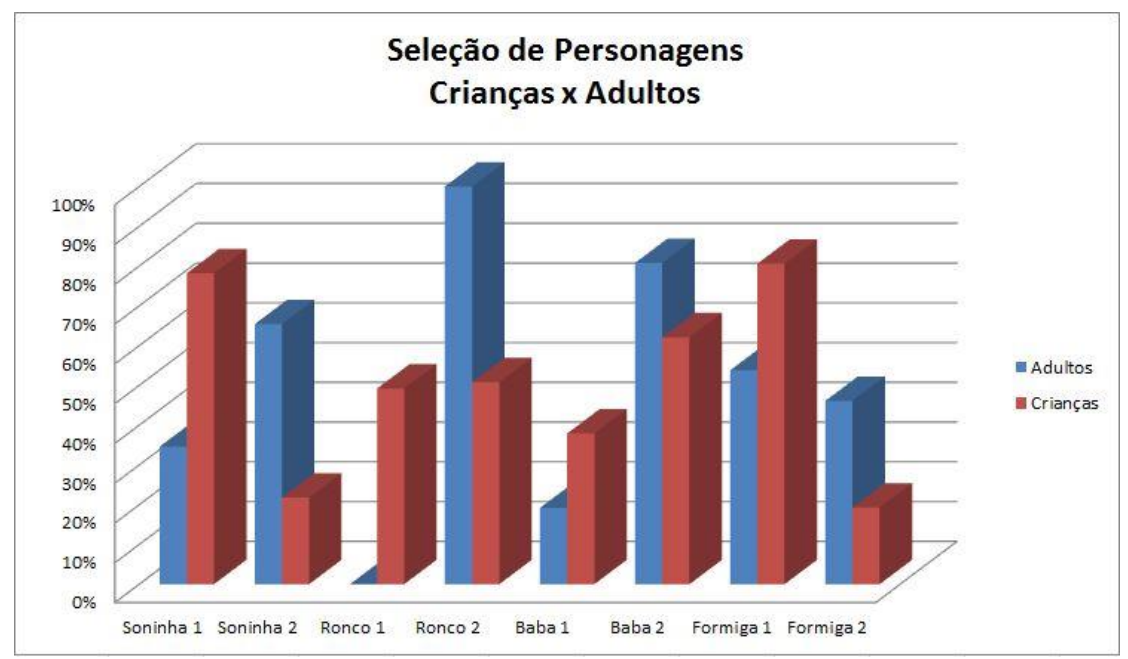

Gráfico 2. Seleção comparativa das amostras de crianças e adultos (gráfico elaborado pelo autor, com base na pesquisa realizada)

Os 61 estudantes entrevistados na escola pública optaram por: Soninha 1(68.9\%); Ronco 1 (54.1\%); Baba 2 (55.7\%) e Formiga 1 (72.1\%).Na rede privada as 25 crianças selecionaram: Soninha 1 (88\%); Ronco 1(68\%) Bába 2 (76\%) e Formiga 1 (84\%). Comparando-se as duas amostras, não observamos diferenças estatisticamente significantes entre a proporção de escolhas destes subgrupos. ( $p>0.05$ ).

Não houve diferenças estatisticamente significantes em relação às escolhas para as diferentes idades, exceto pelo fato das 86 crianças de 7 anos terem optado indistintamente pelo Ronco 1 e Ronco 2 ( $p>0.05$; IC 95\%; 0.477-0.685 e 0.315-0.523). Os demais personagens escolhidos foram: Soninha 1, Baba 2 e Formiga $1(p<0.05)$.

Segundo depoimento das crianças, a personagem Soninha 1 foi escolhida devido suas características de heroína, pois em função das botas, foi associada a imagem da Mulher Maravilha. Os demais personagens foram escolhidos em razão de sua aparência mais simpática, positiva e alegre.

A personagem Soninha 2 e Baba 2 foram escolhidas em razão da delicadeza e fragilidade que exprimem, sugerindo mais infantilidade e suscitando um vínculo protetor. O Ronco 2 e Formiga 1 foram selecionados em função de sua simpatia e expressividade, com características de pro atividade e segurança.

\subsection{Discussão}

Neste estudo, a amostra constituída por adultos e crianças selecionou as personagens Soninha 1, Formiga 1, Baba 2 e Ronco 1 e Ronco 2, indistintamente, sendo escolhidos portanto, personagens de ambas versões visuais, neotônica e mangá.

Quanto às diferenças entre faixa etária, crianças e adultos tiveram preferências distintas em relação à personagem Soninha. As crianças optaram por uma representação "heroica" (Soninha1) que, caracterizada de botas, lembrava a indumentária da mulher maravilha; enquanto os adultos preferiram a versão mais frágil e infantil da personagem (Soninha 2), com óculos, pijama, boneca, cabeça e olhos superdimensionados. Entre as crianças, não houve diferença significante em função da faixa etária ou procedência escolar, ressalva-se apenas que as crianças de 7 anos selecionaram indistintamente as 
personagens Ronco 1 e Ronco 2. Uma das razões para entendermos a diferença de opções entre adultos e crianças é a aparência infantil expressas nas personagens da versão 2, própria do estilo neotônico

A importância de termos realizado o presente ensaio com duas versões visuais diferentes pode ser compreendida quando observamos a evolução de personagens clássicos como o Mickey (USA) e Mônica (Brasil), que no início apresentavam traços menos neotênicos. A exposição destes personagens ao público permitiu aos artistas modificarem suas características, baseando-se em informações oriundas de sua aceitação, sempre indissolúvel do contexto em que estavam inseridos. A primeira versão do Mickey (1928), embora ainda muito distante do que ele representa (um rato que é culturalmente hostilizado), tem um apelo afetivo menor que a representação atual, onde os contornos foram arredondados, as extremidades encurtadas e engrossadas e a cabeça e olhos ampliados, sugerindo características de filhotes (neotenia), os quais tendem a desencadear sentimentos de afeto e proteção, tendo inclusive bases neurofisiológicas para este fenômeno, ou seja, o aumento de atividade dopaminérgica e oxitocinérgica (PETROVIC et al., 2008; DOMESA et al., 2007) que justificariam a preferência dos adultos pela versão 2

Já o que poderia explicar a preferência das crianças pela Soninha 1 , seria a identificação catártica, que ocorre a partir do caráter comportamental das personagens e é um fenômeno frequente no gênero literário $H Q$. Uma heroína como a Mulher Maravilha, com a qual foi associada a imagem da Soninha 1, concretiza a fantasia do "poder" (KHÉDE, 1990). È interessante observar que não é apenas a configuração anatômica que pode caracterizar o herói (beleza, músculos), mas também a sua indumentária. A transformação de Clarck Kent em Super Homem ou do Peter Parker em Homem Aranha passa necessariamente pela troca de roupas (MARNY, 1968). As crianças do nosso estudo foram sensíveis a este fato, identificando a protagonista Soninha $1 \mathrm{com}$ uma heroína, em função das botas utilizadas pela personagem.

De modo geral, pudemos observar que as personagens selecionadas foram aquelas que apresentaram a interface mais amigável e simpática. Esta é uma característica fisionômica esperada em um herói, bem como o queixo quadrado, que pode ser entendido como um traço que identifica pessoas decididas (MARNY, 1968).

As representações mais expansivas favoreceram a identificação de crianças e adultos pois ampliam a possibilidade de projeção de estados emocionais e favorecem a interação não-verbal entre as personagens e o leitor. O humor já foi apontado como um diferencial para a eficiência de campanhas de saúde e as HQs, usualmente chamadas de Comics, têm o humor como elemento essencial, desde sua origem.

Identificamos também que as crianças de 7 anos selecionaram indistintamente Ronco 1 (mangá) e Ronco 2 (neotênico). Entre o público infantil foi a única faixa de idade que não optou pela versão 2 da personagem Ronco. Podemos interpretar este resultado levando em consideração a possibilidade de maior suscetibilidade destas crianças (as mais jovens da amostra) - à massificação do gênero Mangá apresentada pela mídia impressa e pela televisão, o que teria se sobreposto a aparência expressiva e bem humorada da personagem Ronco 2 
O mangá - que significa "desenho irreverente, humorístico" - existe no Japão desde o século 19 e se caracteriza visualmente por meio de closes, caretas, olhos e brilhos super dimensionados, e realismo nas manifestações das emoções expressas no suor, rubor e até um sangramento nasal em momentos de stress da personagem, registrando uma dramaticidade tal, que transcende a expressividade chegando ao humor pela veia caricata. Este estilo hoje é uma importante referência e influência cultural do Japão. No Brasil, que abriga a maior colônia de nipodecendentes fora do Japão, a estética do mangá (ou Anime em sua versão audiovisual) foi inserida há mais de 40 anos e séries como "Fantomas", "A Princesa Safire", "Jaspion", "Cavaleiros do Zodáico", "Pokemon" e "Dragon Ball Z" já contavam com uma legião de fãs (LUYTEN, 2003)

Vale salientar que não observamos diferenças significantes entre os subgrupos de escolas públicas e particulares sugerindo que a classe socioeconômica não tem influência na percepção visual e identificação das crianças com as personagens propostas.

A HQ pode ser um eficiente instrumento de comunicação do gênero de literatura icônico/verbal que, por sua percepção multissensorial, pode se prestar a informar crianças e adultos. Este gênero literário permite o contato com a informação de forma coloquial e lúdica, havendo dados que indicam sua eficiência como recurso didático (VERGUEIRO, SANTOS, 2005; EISNER, 1996; MICHEL, 1976; MCCLOUD, 2000).

Os estúdios Disney, por exemplo, estão envolvidos em campanhas de saúde pública desde 1938 e mais recentemente, organismos mundiais como o Fundo das Nações Unidas para a Infância (UNICEP), a Organização Panamericana de Saúde (OPAS) e a World Health Organization (WHO), utilizam-se de HQs para esclarecer a população sobre doenças e sua prevenção (CARUSO, SILVEIRA, 2009; ROSCHKE, 2006; ARAUJO, CARDOSO, 2007).

Mendes destaca três possibilidades de utilização didática das HQs: A análise crítica das histórias existentes; o desenvolvimento autoral de HQ pela própria criança (que tem a oportunidade de expressar-se) e a utilização das histórias em quadrinhos como um meio de informação e conscientização (DIAS, 2001; ALVES, 2001). Tendo isto em vista, buscamos não nos ater apenas ao caráter instrucional da HQ e pretendemos favorecer também a expressividade da criança, possibilitando que ela venha a colorir a história em quadrinhos. Isto permite que o leitor expresse sua individualidade personalizando sua $\mathrm{HQ}$, ao mesmo tempo em que, metaforicamente, transforma-o em protagonista, dando-lhe a noção de que pode interferir na sua própria história clínica.

Além disso, este recurso também contempla um importante requisito aplicado às políticas públicas, uma vez que reduz consideravelmente os custos do processo de reprodução impressa, utilizando-se apenas 2 cores, ao invés das 4 (quadricromia) usualmente empregadas.

\section{CONCLUSÃO}

Nosso estudo permitiu a criação e seleção de 4 personagens representativos do sono normal e de três distúrbios do sono muito prevalentes. Adultos e crianças deferiram quanto a preferências pelo estilo mangá e neotônico, não tendo ocorrido diferenças de preferências quando consideramos alunos de escolas públicas e privadas. Os resultados 
do presente estudo suportam o desenvolvimento de uma terceira versão híbrida das personagens, que busque contemplar as características principais dos elementos selecionados, tanto por adultos, quanto pelas crianças. As personagens desenvolvidas e selecionadas neste estudo protagonizarão futura série de histórias em quadrinho sobre Distúrbios de Sono, que abordarão: Higiene do Sono, Ronco, Apneia, Síndrome das Pernas Inquietas e a Polissonografia.

\section{REFERÊNCIAS}

ALVES, J.M. Histórias em quadrinhos e educação infantil. Psicologia: ciência e profissão [online], v.21, n.3, p.2-9, 2001

ARAUJO, I.S.; CARDOSO, J.M. [Comics for citizenship] Comunicação e Saúde. Rio de janeiro: Fio Cruz , História Ciência e Saude-Manguinhos, vol.16, n.1, 2007

BALBINI, A.P.S., et al. Pediatricians and sleep-disordered breathing in the child. Revista da Associação Médica Brasileira, v.51, n.2, p.80-86, 2005.

CAMARGO, E.P. et al. Marketing Social: caracterização do paciente do ambulatório de neuro-sono da Unifesp. Revista Neurociências, São Paulo, v.19, n.2, 2011.

CAMARGO, E.P. Is the population properly informed about sleep disorders? Arquivos de Neuro-Psiquiatria. vol.71, n.2, São Paulo, 2013.

CARUSO, F.; SILVEIRA, C. Quadrinhos para a cidadania. Historia, ciência e saúde Manguinhos, v.16, n.1, p.217-236, 2009.

CARVALHO, L.B.C., et al. Cognitive dysfunction in children with sleep-disordered breathing. Journal of Child Neurology, v.20, p.400-404, 2005.

CIRNE, M. A linguagem dos Quadrinhos. Petrópolis: Editora Vozes, 1971.

COX, M. Desenho da criança. São Paulo: Martins Fontes, 2000.

DIAS, C. A. Considerações sobre elaboração de currículos para formação de psicólogos: a partir de uma perspectiva didática. Psicologia: ciência e profissão, v.21, n.3, p. 36-49, 2001.

DOMESA, G. et al. Oxytocin Improves "Mind-Reading" in Humans. Biological Psychiatry, 2007, v. 61, n 6, p.731-733

DONIS, A. D. Sintaxe da Linguagem Visual. São Paulo: Martins Fontes, 1997.

EISNER, W. Quadrinhos e Arte Sequencial. São Paulo: Martins Fontes, 1989. 154p

FAWDRY, R. Prescribing the leaflets. Brazilian Journal Hospital Medicine, v.5, n.10, p. 551-553, 1994.

FRUTIGER, A. Sinais e Símbolos. SP: Martins Fontes, 1999.

GOZAL, D, O'BRIEN, L, ROW, BW. Consequences of snoring and sleep disordered breathing in children. Pediatric Pulmonology, 37 suppl 26, p. 166-168, 2004.

JULIANO, M.L., et al. Mouth breathing children have cephalometric patterns similar to those of adult patients with obstructive sleep apnea syndrome. Arquivos de NeuroPsiquiatria, v.67,n.3b, 2009.

KHÉDE, S. S. Personagens da Literatura Infanto-Juvenil. São Paulo: Editora Ática, 1990.

LUYTEN, S.M.B. Mangá Produzido no Brasil : Pioneirismo, Experimentação e Produção Intercom - Sociedade Brasileira de Estudos Interdisciplinares da Comunicação. In: XXVI Congresso Brasileiro de Ciências da Comunicação, Belo Horizonte, 2 a 6 Set., 2003. 
MACHADO, M.A.C. et al. Clinical Co-morbidities in obstructive sleep apnea treated with mandibular repositioning appliance. Respiratory Medicine, v.100, p. 988-995, 2006.

MARNY, J. Sociologia das Histórias aos Quadrinhos. Porto: Civilização Editora, 1970

MCCLOUD, S. Reinvinting Comics. Nova lorque: Paradox Press, 2000.

MICHEL, P. La Bande Dessinée. Paris: Librairie Larousse, 1976.

Ottawa Charter for Health Promotion. First International Conference on Health

Promotion. Ottawa, 21 November 1986 - WHO/HPR/HEP/95. Disponível em:

<http://www.who.int/hpr/NPH/docs/ottawa_charter_hp.pdf> .Acesso em jan. 2011

PARKER, I. Qualitative Psychology. Buckingham: Open University Press, 2004, 200p

PARTINEN, M.; HUBLIN, C.G. Epidemiology of sleep disorders. In: Principles and practice

of sleep medicine. Kryger, M.H.; Roth T.; Dement, W.C. (Editors), 3 ed, p.558-79. W.B.

Saunders Company, Philadelphia, 2000.

PETROVIC, P. et al. Oxytocin Attenuates Affective Evaluations of Conditioned Faces and Amygdala Activity. The Journal of Neuroscience, v.28, n.26, p.6607-6615, 2008.

RAMA, A.; VERGUEIRO, W. (orgs). Como Usar as histórias em Quadrinhos na Sala de Aula. São Paulo: Contexto, 2004.

ROSCHKE, M.A.C. (ed). Evaluation in processes of continuing education and training in health: experiences and lessons. Washington, D.C; Organización Panamericana de la Salud; 2006.

ROZEMBERG, B.; SILVA, A.P.P.; VASCONCELOS-SILVA, P.R. Impressos hospitalares e a dinâmica de construção de seus sentidos: o ponto de vista dos profissionais de saúde. Cadernos de Saúde Pública, v.18, n.6, p.1685-1694, 2002.

SANTOS-SILVA, R. et al. Sao Paulo Epidemiologic Sleep Study: Rationale, design, sampling, and procedures. Sleep Medicine, n.10, p.679-685, 2009.

SCHALL, V.T.; JURBERG,P; ROZEMBERG,B; VASCONCELLOS, M.C. Ciranda da Saúde: Aprendendo e Ensinando através de Histórias infantis no 1 grau. Ciência e Cultura, 38 (supl.7), p.159, 1986.

TEIXEIRA, R.R., CYRINO, A.P. As ciências sociais, a comunicação e a saúde Social. Ciência e Saúde Coletiva, v.28, n.1, 2003.

VERGUEIRO, W.; SANTOS, R.E. A pesquisa sobre histórias em quadrinhos na Universidade de São Paulo: análise da produção de 1972 a 2005. UN/revista, v.1, n.3, p.1-12, 2006.

Agradecimentos: À Yandra Mello, pelo apoio na coleta de dados e Glauber Rocha, pelos mangás. 